\title{
"Translocal" narration of environmental issues through graphic novels: two Italian case studies
}

\author{
Antonella Rinella $^{1}$ iD, Federica Epifani ${ }^{2}$ \\ ${ }^{1}$ University of Salento, Department of History, Society and Human Studies, 73100 Lecce, Italy; \\ ${ }^{2}$ University of Salento, Department of Cultural Heritage, 73100 Lecce, Italy; \\ antonella.rinella@unisalento.it (AR); federica.epifani@unisalento.it (FE)
}

Received: 8 November 2020; Revised: 17 January 2021; Accepted: 21 January 2021;

Published online: 29 January 2021

\begin{abstract}
The prevalence of mainstream media as source of information on environmental issues and their tendency to draw global attention around a few major, dramatic environmental disasters (melting of glaciers in the Arctic, desertification and drought in the African continent, deforestation of the Amazon, oil pollution in the oceans, etc.), is creating in less conative readers/audience a lack of awareness of the damages suffered in the local territorial systems to which they belong and low willingness to collective action. Therefore, crossing and comparing the highest possible number of sources of information, preferring those that can generate a proactive response to events and themes concerning environmental sustainability and highlight deep local/global interconnections, is essential to attain an independent, critical, and responsible narration. After shortly illustrating some theoretical and methodological considerations developed in the areas of popular geopolitics, anti-geopolitics and ecocriticism, this paper reviews two Italian graphic novels providing a bottom-up representation of local environmental issues: the first one deals with the eutrophication of the Orbetello Lagoon (Tuscan Maremma); the second one concerns the collapse of the tailings dams of the Prestavèl fluorite mines located in Val di Stava (Trentino Alto Adige), a disaster that caused the death of 268 people. We will try to point out how the authors, who are totally "embedded" in their works, provide a "translocal" narration, condemning effectively and immediately the environmental damages in the territorial context analysed and, at the same time, highlighting the interconnections between such site-specific events and global sustainability, inviting readers to adopt an holistic view of the nature-culture relationship, beyond the anthropocentric and instrumentalist production model which considers biosphere a mere tool to satisfy the contingent needs of contemporary society.
\end{abstract}

Key words: popular geopolitics, anti-geopolitics, ecocriticism, graphic novel, Italian environmental issues, Orbetello Lagoon, Val di Stava.

Citation: Rinella, A., Epifani, F. (2021). "Translocal” narration of environmental issues through graphic novels: two Italian case studies. Central European Journal of Geography and Sustainable Development, 3(1), 5-20. https://doi.org/10.47246/CEJGSD.2021.3.1.1

https://doi.org/10.47246/CEJGSD.2021.3.1.1

\section{| Full text |}

